\title{
MicroRNAs as regulators of drug abuse and immunity
}

\author{
KAI ZHANG ${ }^{1}$ XUXIU JING ${ }^{2}$, GUOQIANG WANG
}

${ }^{1}$ Wuxi Mental Health Center, Nanjing Medical University, Wuxi, China

${ }^{2}$ Shanghai Mental Health Center, Shanghai Jiao Tong University School of Medicine, Shanghai, China

\begin{abstract}
MicroRNAs (miRNAs) are 20-22 nucleotide non-coding RNAs that participate in gene regulation. They bind to 3'-untranslated regions of their mRNA targets, inhibiting the transcripts' translation and/ or destabilizing them. Chronic drug abuse induces changes of miRNAs expression in the brain, which is thought to contribute to addictive behaviors. Lots of miRNAs have been identified to play critical roles in the development of drug addiction. Moreover, miRNAs have been shown to play critical roles in a broad array of biologic processes, including regulation of the cell cycle, oncogenic transformation, immune cell regeneration and differentiation, and psychiatry disorders. We hypothesized that chronic drug abuse leads to aberrant expression of several miRNAs, and then aberrant miRNAs influence the innate and adaptive immunity, especially differentiation and function of $T$ cells and B cells, through down-regulated miRNAs' target gene expression. Characterization of miRNA actions is important and has high potential effect for the management of drug addiction and immunity diseases. miRNAs are potential biomarkers, and the modulation of their expression can be used for therapeutic purposes.
\end{abstract}

Key words: innate immunity, microRNA, immunity, drug abuse, adaptive immunity.

(Cent Eur J Immunol 2016; 41 (4): 426-434)

\section{Introduction}

In the year 2011 there were approximately 14.0 million drug users between the ages of 15 and 64 years, 1.6 million drug abusers with HIV and 0.2 million drug-related deaths [1]. It is important to note that most of the drug-related deaths were in young people and could have been prevented. Drug abuse is a chronic brain disease with severe social and economic consequences that are associated with significant mortality and morbidity [2]. Abuse substances, such as opiates, cocaine, marijuana, alcohol, and nicotine, all have been reported to impair the immune system and enhance or suppress immune response cell function [3-7]. Additionally, an increasing number of studies have focused on the associations between drug abuse and the immune system. More and more studies have focused on non-coding microRNAs (miRNAs) at the molecular level.

miRNAs are 20-22 nucleotide non-coding RNAs that regulate gene expression by binding to the 3'-untranslated regions (3'-UTRs) of their mRNA targets. Because of this mechanism, miRNAs silence or prevent the translation of their target genes. Previous studies have shown that miRNAs are master regulators of genes and their networks. Aberrant miRNA expression has been closely linked to various diseases, including psychiatric disorders, neuronal development, and immune-related disorders [8-11].
Our goals in this review were to summarize the research results of aberrant expression of miRNAs after chronic drug abuse and cite specific examples of how miRNAs affect the innate and adaptive immune systems. We concentrated on the intermediate effects of specific miRNAs involved in chronic drug abuse and immune system diseases.

\section{Chronic drug abuse changes the expression of microRNAs}

Chronic drug abuse up-regulates or down-regulates the expression of related genes, that contribute to drug addiction behaviours such as craving and seeking. As described in previous studies, a large number of genes, such as brain-derived neurotrophic factor (BDNF), cAMP response element binding protein (CREB), and methyl $\mathrm{CpG}$ binding protein 2 (MeCP2), have been shown to play critical roles in the development of drug addiction. More importantly, many of these genes require a complex network to exert their regulatory functions on drug abuse. If we were able to identify the master regulator of this network, we could provide insights into safe and effective therapies to treat drug addiction. Unfortunately, we do not completely understand this regulatory network and the master regulator remains unknown.

Correspondence: Guoqiang Wang, Wuxi Mental Health Center, Nanjing Medical University, 156 Qianrong Road, 214151 Wuxi, China, e-mail: 543918@163.com

Submitted: 9.10.2015; Accepted: 2.05.2016 
Table 1. miRNAs in drug abuse and immunity

\begin{tabular}{|c|c|c|c|c|c|}
\hline Drug & microRNA & Regulation & Reference & Immunity & Reference \\
\hline \multirow[t]{8}{*}{ Cocaine } & miR-212 & Up & $\begin{array}{l}\text { Hollander et al. } 2010 \text { [13]; } \\
\text { Im } \text { et al. } 2010 \text { [14]; Xu et al. } 2013 \text { [15] }\end{array}$ & $\begin{array}{l}\text { Innate } \\
\text { immunity }\end{array}$ & $\begin{array}{l}\text { Wanet et al. } 2012 \text { [62]; } \\
\text { Nahid } \text { et al. } 2013 \text { [63] }\end{array}$ \\
\hline & miR-132 & Up & Nudelman et al. 2010 [16] & $\begin{array}{c}\text { Innate } \\
\text { immunity }\end{array}$ & $\begin{array}{l}\text { Wanet et al. } 2012 \text { [62]; } \\
\text { Nahid } \text { et al. } 2013 \text { [63] }\end{array}$ \\
\hline & miR-181a & Up & $\begin{array}{l}\text { Chandrasekar et al. } 2009 \text { [18]; } \\
\text { Chandrasekar et al. } 2011 \text { [19]; } \\
\text { López-Bellido et al. } 2012 \text { [20] }\end{array}$ & & \\
\hline & miR-124 & Down & $\begin{array}{l}\text { Chandrasekar et al. } 2009 \text { [18]; } \\
\text { Chandrasekar } \text { et al. } 2011 \text { [19] }\end{array}$ & & \\
\hline & let-7d & Down & $\begin{array}{l}\text { Chandrasekar et al. } 2009 \text { [18]; } \\
\text { Chandrasekar } \text { et al. } 2011 \text { [19] }\end{array}$ & & \\
\hline & $\operatorname{miR}-133 b$ & Down & $\begin{array}{l}\text { Chen } \text { et al. } 2013 \text { [22]; } \\
\text { Barreto-Valer } \text { et al. } 2012 \text { [23] }\end{array}$ & & \\
\hline & miR-134 & Up & Chen et al. 2013 [22] & & \\
\hline & miR-22 & Up & Chen et al. 2013 [22] & & \\
\hline \multirow[t]{5}{*}{ Nicotine } & miR-21 & $\mathrm{Up}$ & $\begin{array}{l}\text { Huang and Li } 2009 \text { [25]; } \\
\text { Zhang et al. } 2014 \text { [26] }\end{array}$ & $\begin{array}{c}\text { Innate } \\
\text { immunity }\end{array}$ & Sheedy et al. 2010 [65] \\
\hline & & Down & $\begin{array}{l}\text { Maccani et al. } 2010 \text { [27]; } \\
\text { Shan } \text { et al. } 2009 \text { [28]; } \\
\text { Wang et al. } 2014 \text { [29] }\end{array}$ & $\begin{array}{l}\text { Innate } \\
\text { immunity }\end{array}$ & Chen 2011 [64] \\
\hline & miR-335 & Up & Huang and Li 2009 [25] & & \\
\hline & miR-146a & Down & $\begin{array}{l}\text { Maccani et al. } 2010 \text { [27]; } \\
\text { Shan } \text { et al. } 2009 \text { [28]; } \\
\text { Wang et al. } 2014 \text { [29] }\end{array}$ & $\begin{array}{l}\text { Innate } \\
\text { immunity } \\
\text { Adaptive } \\
\text { immunity }\end{array}$ & $\begin{array}{c}\text { Taganov et al. } 2006 \text { [46]; } \\
\text { Hou et al. } 2009 \text { [47]; } \\
\text { Chassin et al. } 2010 \text { [48]; } \\
\text { Pauley et al. } 2011 \text { [49]; } \\
\text { Rebane } \text { et al. } 2014 \text { [50]; } \\
\text { Schulte } \text { et al. } 2013 \text { [51]; } \\
\text { Curtale } \text { et al. } 2010 \text { [77]; } \\
\text { Lu et al. } 2010 \text { [78]; } \\
\text { Rusca and Monticelli } 2011 \text { [79] }\end{array}$ \\
\hline & miR-133 & Down & $\begin{array}{l}\text { Shan et al. } 2009 \text { [28]; } \\
\text { Wang } \text { et al. } 2014 \text { [29] }\end{array}$ & & \\
\hline \multirow[t]{4}{*}{ Opiate } & let-7 & Up & Wu et al. 2009 [31] & & \\
\hline & miR-23b & Up & He et al. 2010 [32] & & \\
\hline & miR-190 & Up & Zheng et al. 2010 [33] & & \\
\hline & $\operatorname{miR}-133 b$ & Down & Zheng et al. 2010 [33] & & \\
\hline \multirow[t]{6}{*}{ Amphetamine } & miR-29a & Up & Lippi 2011 & & \\
\hline & miR-29b & Up & Lippi 2011 & & \\
\hline & miR-182 & Up & Lippi 2011 & & \\
\hline & miR-183 & Up & Lippi 2011 & & \\
\hline & miR-181a & Up & Saba et al. 2012 [21] & $\begin{array}{l}\text { Adaptive } \\
\text { immunity }\end{array}$ & $\begin{array}{l}\text { Ebert et al. } 2009 \text { [66]; } \\
\text { Li } \text { et al. } 2007 \text { [67]; } \\
\text { Li et al. } 2012 \text { [68] }\end{array}$ \\
\hline & miR-9 & Up & Tatro et al. 2013 [34] & & \\
\hline \multirow[t]{4}{*}{ Alcohol } & miR-21 & Down & Sathyan et al. 2007 [35] & & \\
\hline & miR-335 & Down & Sathyan et al. 2007 [35] & & \\
\hline & miR-9 & Down & Sathyan et al. 2007 [35] & & \\
\hline & miR-153 & Down & Sathyan et al. 2007 [35] & & \\
\hline
\end{tabular}


Table 1. miRNAs in drug abuse and immunity

\begin{tabular}{|c|c|c|c|c|c|}
\hline Drug & microRNA & Regulation & Reference & Immunity & Reference \\
\hline & miR-382 & Down & Wang et al. 2009 [36] & & \\
\hline & miR-124a & Down & Bahi and Dreyer 2013 [37] & & \\
\hline & $\operatorname{miR}-29 b$ & Down & Qi et al. 2014 [38] & & \\
\hline & miR-124 & Down & Mizuo et al. 2012 [39] & & \\
\hline & miR-9 & Up & Pietrzykowski et al. 2008 [40] & & \\
\hline & miR-124 & Up & Dong et al. 2014 [42] & & \\
\hline & miR-206 & Up & Tapocik et al. 2013 [41] & & \\
\hline & miR-181a & Up & Asquith et al. 2014 [44] & & \\
\hline & $\operatorname{miR}-221$ & Up & Asquith et al. 2014 [44] & $\begin{array}{c}\text { Innate } \\
\text { immunity }\end{array}$ & Lu et al. 2011 [59] \\
\hline & $\operatorname{miR}-155$ & Up & Asquith et al. 2014 [44] & $\begin{array}{c}\text { Innate } \\
\text { immunity } \\
\text { Adaptive } \\
\text { immunity }\end{array}$ & $\begin{array}{c}\text { Schulte et al. } 2013 \text { [51]; } \\
\text { Curtis } \text { et al. } 2015 \text { [52]; } \\
\text { Cai } \text { et al. } 2012 \text { [53]; } \\
\text { Ghorpade } \text { et al. } 2012 \text { [54]; } \\
\text { Koch } \text { et al. } 2012 \text { [55]; } \\
\text { Cardoso } \text { et al. } 2012 \text { [56]; } \\
\text { Wang } \text { et al. } 2010 \text { [57]; } \\
\text { Richmond et al. } 2015 \text { [58]; } \\
\text { Lu } \text { et al. } 2011 \text { [59]; } \\
\text { Zhou et al. } 2010 \text { [60]; } \\
\text { Martinez-Nunez et al. 2009 [61]; } \\
\text { Vigorito et al. } 2013 \text { [69]; } \\
\text { Blüml } \text { et al. } 2010 \text { [71]; } \\
\text { O'Connell et al. } 2010 \text { [72]; } \\
\text { Rodriguez et al. } 2007 \text { [73]; } \\
\text { Thai } \text { et al. } 2007 \text { [74]; } \\
\text { Cardoso et al. } 2012 \text { [75]; } \\
\text { Lu et al. } 2009 \text { [78]; } \\
\text { Zhang } \text { et al. } 2012 \text { [84]; } \\
\text { Chen } \text { et al. } 2014 \text { [85]; } \\
\text { Sandhu } \text { et al. } 2012 \text { [86]; } \\
\text { Dorsett } \text { et al. } 2008 \text { [87] }\end{array}$ \\
\hline
\end{tabular}

Interestingly, previous studies have shown that miRNAs are master gene regulators and play critical roles in the regulation of the cell cycle, immune cell regeneration and differentiation, cancer, and psychiatry disorders. Consistent with these diverse roles, recent studies have detected many roles for miRNAs in chronic drug abuse.

\section{Cocaine}

Cocaine is a central nervous system stimulant that exerts widespread effects in the striatum [12]. Three studies have demonstrated that chronic cocaine administration increases the expression of miR-212 in the dorsal striatum in rats [13-15]. Further results indicated that exogenous miR-212 in the striatum decreases addicted rat cocaine intake behaviours. Finally, Kenny's group demonstrated that miR-212 controls drug intake by activating the CREB gene. Therefore, miR-212 maybe a protective factor for compulsive cocaine intake. The same study also illustrated that there is a homeostatic negative balance between
miR-212 and MeCP2. More importantly, the interactive balance between miR-212 and MeCP2 coincided with cocaine sensitization reward effects [14]. Interestingly, chronic cocaine use also increased miR-132 expression in the striatum of rats [16]. miR-212 and miR-132 have overlapping seed regions, and a homeostatic relationship between miR-132 and MeCP2 was observed in brain cortical neurons [17]. It is possible that miR-132 is also a protective factor for compulsive cocaine intake.

Chronic cocaine exposure also increases miR-181a expression [18-20]. Aberrant expression of miR-181a, which binds to the 3'-UTR of the GluA2 subunit of the AMPA receptor (GRIA2), influences the function of the GABA system [21]. Chandrasekar and Dreyer et al. showed that chronic cocaine abuse decreases miR-124 and let-7d levels. miR-124 and let-7d down-regulate the expression of BDNF and the dopamine receptor 3 (DRD3) gene, respectively. When these miRNAs are over expressed in the NAc of rats, an intensive conditioned place preference (CPP) 
for cocaine was observed $[18,19]$. One Chinese study indicated that repeated cocaine exposure and subsequent abstinence change the expression of various miRNAs, including miR-133b, miR-134, and miR-22 [22]. Another study demonstrated that chronic cocaine use led to abnormal miR-133b expression [23].

\section{Nicotine}

To date, there have been few clinical studies published that have focused on the relationship between miRNA regulation and nicotine abuse [24]. Most studies suggest that chronic nicotine abuse up-regulates the expression of miR-21, which is a critical master regulator of the immune system. By culturing rodent neuronal cells, Huang and $\mathrm{Li}$ found that miR-21 and miR-335 were up-regulated by a 100- $\mu \mathrm{M}$ nicotine exposure [25]. Zhang et al. found that miR-21 was over-expressed in oesophageal tissue samples after smoking and that miR-21 up-regulation by nicotine was also detected in cell lines [26]. Notably, smoking during pregnancy is correlated with aberrant miRNA expression and leads adverse pregnancy outcomes [27]. Using three immortalized placental cell lines, Maccani et al. found that miR-21 and miR-146a were significantly down-regulated in placentas exposed to cigarette smoke compared to controls [27]. Aside from miR-21 and miR146a, Shan et al. and Wang et al. showed that chronic nicotine abuse down-regulates miR-133 in a nicotine abuse model $[28,29]$. The above results suggest that some miRNAs, such as miR-21, miR-146a, and miR-133, are sensitive to nicotine exposure and that cigarette smoking may affect downstream signalling by changing the expression of miRNAs.

In a clinical study, Takahashi determined whether chronic cigarette abuse substantially alters the plasma miRNA levels via TaqMan microRNA array analysis [30]. They found that 43 miRNAs were significantly higher in the plasma of smokers compared with healthy individuals. Of the aberrant miRNAs, miR-21 displayed a 3-fold increase in expression in smokers compared to non-smokers; miR-21 is known to be involved in the development of immune system disorders.

\section{Opiates}

Chronic morphine exposure led to the aberrant expression of let-7 and miR-23b. Using cells and a mouse morphine abuse model, He et al. determined that morphine significantly up-regulated let-7 expression. They also found that let-7 binds to the morphine receptor (MOR) mRNA 3'-UTR and represses MOR expression. These results suggest that let-7 plays a key role in morphine abuse [31]. Aside from let-7, Wu's group demonstrated that long-term morphine treatment increases miR-23b expression [32] and that miR-23b binds to the OPRM1 mRNA and controls OPRM1 expression.
Using microRNA microarray analysis, scientists determined that morphine and fentanyl induced similar changes in the expression of miR-224, miR-331, and miR-365 but also had an agonist effect on the expression of miR-20a, miR-184, miR-190, and miR-301 [33]. More importantly, they found that fentanyl, but not morphine, increased miR-190 levels. After validation of the microarray results by qPCR, researchers observed that the miR-133b levels were decreased in $24 \mathrm{hpf}$ zebrafish embryos exposed to morphine.

\section{Amphetamines}

Researchers found consistent up-regulation of the $\mathrm{miR}-29 \mathrm{a} / \mathrm{b}$ and miR-182/183 clusters in most brain regions when mice were exposed to $5 \mathrm{mg} / \mathrm{kg}$ amphetamine for 5 days. Additionally, miR-181a is strongly enriched in the nucleus accumbens, suggesting that miR-181a might regulate the expression of synaptic proteins at this specific site [21]. There is only one study that focuses on miRNA expression in methamphetamine (MA) abusers [34]. By screening MA abuser and control frontal cortex autopsy tissues, the authors found that miR-9 expression was significantly increased in MA abusers. To verify this result, SH-SY5Y cells were exposed to MA. Based on the q-PCR results, it is worth noting that miR-9 expression was remarkably increased in the cells exposed to MA compared to the controls. Later, they found that miR-9 binds to the calcium-activated channel subfamily $\mathrm{M}$ alpha member 1 (KCNMA1) and negatively regulates its expression. Their results suggest that elevated miR-9 expression, which is induced by MA, leads to the suppression of KCNMA1. As previous studies have reported, KCNMA1 may affect neurotransmitter release in dopaminergic neurons.

\section{Alcohol}

In addition to cocaine and other psychomotor stimulants, chronic alcohol abuse has also been shown to regulate miRNA expression. A particularly intriguing example for the role of miRNAs in chronic alcohol abuse comes from a study by Sathyan et al. [35]. Using cell culture experiments, Sathyan et al. identified the following miRNAs as being alcohol-sensitive: (1) miR-21, (2) miR-335, (3) miR-9, and (4) miR-153. Alcohol significantly suppressed the expression of these four miRNAs. Wang also showed that chronic alcohol consumption decreased miR-382 expression in the accumbens of rats [36]. They showed that miR-382 negatively regulates dopamine D1 receptor expression, which plays an important role in the reward system. Another study showed that chronic alcohol intake decreased miR-124a expression in the dorsolateral striatum of rats and that the over expression of miR-124a decreased alcohol-induced CPP and reduced alcohol consumption behaviours in rats [37]. Using a neuronal model, chronic alcohol exposure suppressed miR-29b expression and 
promoted neuronal apoptosis. When miR-29b was over expressed in the neuronal model, it protected the neurons against apoptosis [38]. When abstinence was examined in alcohol-addicted rodents and cells, withdrawal caused dynamic molecular and cellular changes. Mizuo et al. found that the miR-124 levels were reduced in the limbic forebrain following alcohol withdrawal [39].

In contrast to the studies mentioned above, chronic alcohol use has also been shown to elevate the levels of specific miRNAs, including miR-9, miR-124, miR-181a, and miR-155. Pietrzykowski et al. exposed rats to chronic intermittent amounts of alcohol and observed an increase in miR-9 expression. Up-regulation of miR-9 led to the degradation of BK splice variants [40]. Similarly, Tapocik et al. and Dong et al. have shown that escalating levels of alcohol intake can increase the expression of miR-206 and miR-124, respectively [41, 42]. It should be noted that miR-206 negatively regulates the expression of brain-derived neurotropic factor (BDNF), which is deemed to play a vital role in the motivational effects of alcohol and other addictive drugs [43]. Asquith revealed that chronic alcohol dependence up-regulated miR-181a and miR-221 in the peripheral blood mononuclear cell (PBMC) and miR-155 in the colon of rats [44].

In addition to identifying changes in the miRNA levels after alcohol treatment in animal models and cell lines, Lewohl analysed post-mortem brains from 14 alcoholics and 13 matched healthy controls. Approximately 35 miRNAs were markedly up-regulated in the alcoholics compared to the controls [45]. Notably, miR-146a, which is associated with immunity disorders, was up-regulated in the frontal cortex of alcoholics [46].

Altogether, the examined studies illustrate that miRNAmediated gene regulation plays a critical role in the complicated interactions involved in chronic exposure to addictive drugs. We hypothesize that chronic drug abuse leads to the aberrant expression of several miRNAs. These aberrantly expressed miRNAs influence innate and adaptive immunity, specifically the differentiation and function of $\mathrm{T}$ and $\mathrm{B}$ cells, by down-regulating the expression of the miRNA target genes.

\section{miRNAs in immunity}

The human body has two main defence systems against foreign invaders, the innate and adaptive immune systems. The innate immune system, also known as the non-specific immune system, is a natural immune defence system, which was formed during the development and evolution of the body, that has nonspecific defence functions immediately after birth. The following are types of innate immune cells: (1) phagocytes, (2) dendritic cells (DCs), (3) NK cells, (4) NKT cells. In contrast, the adaptive immune system, also called the acquired immune system, is developed through asymptomatic infection or artificial inoculation and prepares the body to fight infection. $\mathrm{T}$ and $\mathrm{B}$ lymphocytes are essential to the adaptive immune system.

Generally, miRNAs can affect immune system function in two ways. miRNAs can control differentiation of innate and adaptive immune responses in the mammalian immune system. In the bone marrow and thymus, miRNAs are involved in cell function and differentiation, specifically for T and B lymphocytes.

\section{miRNAs in innate immunity}

The innate immune system is characterized by rapid responses to pathogens. Emerging data have identified the important contribution of miRNAs to the development and function of innate immune cells. Among the miRNAs that influence the innate immune system, miR-146a, miR-155, and miR-132 have been the most intensively studied.

miR-146a is located on chromosomes 5 and extensively expressed in the hematopoietic system. Taganov first reported that miR-146a might be involved in the innate immune response [46]. miR-146a is an $\mathrm{NF}-\kappa \mathrm{B}-$ dependent miRNA that targets the NF- $\kappa \mathrm{B}$ pathway, which is the central pathway in innate immunity. Studies reported that miR-146a directly targets and represses several downstream signalling molecules, including IL-1 receptor associated kinase 1 (IRAK1), IL-1 receptor associated kinase 2 (IRAK2), and TNF receptor-associated factor 6 (TRAF6) [47]. Both of these genes encode key adaptor molecules downstream of Toll-like and cytokine receptors. Chassin demonstrated that miR-146a repressed IRAK1, and induced intestinal epithelial innate immune tolerance which will be protected neonates from bacteria-induced epithelial damage [48]. Based on the results of Sjögren's syndrome patients and mouse model, Pauley revealed miR-146a had a role in increasing phagocytic activity and suppress inflammatory cytokine production in human monocytic THP-1 cells [49]. With tissue culture and in vivo experiments, Rebane demonstrated that miR-146a-mediated repression in allergic skin inflammation occurs partially through direct targeting IRAK1 [50].

miR-155 is another key miRNA that plays a role in the innate immune system $[51,52]$. miR- 155 has been shown to greatly influence macrophage and DC functions [53,54]. In macrophages, a number of stimuli, such as chronic alcohol abuse, enhance miR-155 expression via NF-кB; miR-155 is involved in macrophage polarization and the regulation of apoptosis [55]. From Wang's research, the expression of miR-155 was markedly up-regulated in macrophages infected with vesicular stomatitis virus. In subsequent studies, scientists demonstrated that miR-155 positively regulates the host antiviral innate immune response through its target suppressor of cytokine signalling 1 (SOCS1) [56, 57]. When mouse macrophages were exposed to lipopolysaccharide (LPS), the expression of miR- 
155 was increased, which then down-regulated tumour-suppressor gene QKI expression [58]. miR-155 also plays a key role in regulating DC activation [59]. Zhou found that after Toll-like receptor 7 (TLR7) stimulation, miR-155 was highly expressed in plasmacytoid dendritic cells [60]. A study by Martinez-Nunez showed that miR-155 down-regulates DC-specific intercellular adhesion molecule-3 grabbing non-integrin (DC-SIGN), which directly affects the maturation of human DCs [61]. In conclusion, miR-155 can either strengthen or suppress innate immune responses in macrophages and DCs depending on the type of stimulation.

Like miR-155, miR-132 is up-regulated in response to LPS [46]. Previous studies have shown that miR-132 and miR-212 have similar gene structures and belong to the same miRNA family [62]. Recent studies have demonstrated that miR-132 targets cyclic AMP-responsive element-binding protein (CREB) [16]. In monocytes and primary macrophages, the expression of miR-132 and miR-212 was up-regulated rapidly [63]. The rapid increase in miR-132 expression induces tolerance to subsequent stimulation in monocytes by directly targeting interleukin-1 receptor-associated kinase 4 (IRAK4).

Besides miR-146a, miR-155 and miR-132, miR-21 also controls innate immune responses [64]. In human peripheral blood mononuclear cells, LPS stimulation down-regulated the expression of programmed cell death 4 (PDCD4). This down-regulation was due to the induction of miR-21 through the adaptors MyD88 and NF- $\kappa B$. When the miR-21 precursor was transfected into cells, miR-21 blocked NF- $\kappa$ B pathway activity and increased the production of interleukin-10 (IL-10). Thus, miR-21 regulates PDCD4 expression following LPS stimulation [65].

The studies described above clearly suggest that specific miRNAs, such as miR-146a, miR-155, miR-132/miR-212, and miR-21, play an important role in the regulation of innate immunity. This mechanism includes suppressing the expression of the positive signalling proteins, while down-regulating numerous miRNAs during innate immune cell activation. All of these mechanisms are important for host defences and are helpful for initiating antigen-specific responses by adaptive immune system cells.

\section{miRNAs in adaptive immunity}

The adaptive immune system mainly consists of $\mathrm{T}$ and B lymphocytes. miRNAs are emerging as critical regulators in the development and function of the adaptive immunity system. The contribution of specific miRNAs, such as miR-181a, miR-155, and miR-146, to the adaptive immune response is remarkable during the differentiation and functional processing of $\mathrm{T}$ and $\mathrm{B}$ lymphocytes.

miR-181a is widely expressed during the $\mathrm{T}$ cell differentiation process. This miRNA specifically modulates $\mathrm{T}$ cell antigen receptor (TCR) response [66]. Li and colleagues indicated that enhanced expression of miR-181a augmented the sensitivity to peptide antigens in mature
T cells, and vice versa [67]. When inhibited miR-181a level reduced sensitivity, and then impairs both positive and negative selection of $\mathrm{T}$ cells. Interestingly, in immature $\mathrm{T}$ cells, higher miR-181a level means greater $\mathrm{T}$ cell sensitivity. Based on the results, we concluded that miR-181a acts as a regulator of $\mathrm{T}$ cell antigen sensitivity. Similar to this research results, another group found that decline in miR-181a expression impaired $\mathrm{T}$ cell receptor sensitivity, respectively [68].

Another miRNA, miR-155, is also widely expressed in immune cells [69]. There are reports that miR-155 is involved in disparate facets of the adaptive immune system [70]. In a study of miR-155 deficiency mice, the generation of pathogenic autoreactive $\mathrm{T}$ cells was greatly reduced compared with controls [71]. In the hematopoietic system, miR-155 promote the development of manifold $\mathrm{T}$ cells, such as the T helper 17 (Th17) cell and Th1 cell subsets [72]. In addition, according to studies by Rodriguez et al. and Thai et al, miR-155 is essential for Th2 differentiation $[73,74]$. The above results support miR-155 as having a critical role in the inflammatory response pathway. Notably, miR-155 is also associated with regulatory $\mathrm{T}$ (Treg) cell function. Indeed, miR-155 sustains Treg cell proliferation and homeostasis and down-regulates suppressor of cytokine signalling 1 (SOCS1) $[56,75,76]$. Therefore, miR-155 appears to regulate $\mathrm{T}$ cell (and B cell, see below) differentiation and function.

Additional Treg function to regulate microRNA is provided by miR-146a. miR-146a is low in naive human $\mathrm{T}$ cells, but is enhanced expression in human memory $\mathrm{T}$ cells [77]. Results from miR-146a-deficient mice showed an increase in the percentage of INF $\gamma$-producing T-cell subset with absence of miR-146a [78]. More importantly, Lu's group reported that miR-146a is critical for Treg suppressor functions among the miRNAs prevalently expressed in Treg cells. miR-146a targets signal transducer and activator transcription 1 (Stat1) in Treg cells. Aberrant expression of this miRNA enhances Stat 1 expression and activation. Aberrant expression of miR146a also breaks down immunological tolerance, which has been shown to manifest as fatal IFN $\gamma$-dependent immune-mediated lesions [46, 79].

A number of miRNAs, including miR-181, miR-150, and miR-34a, have been reported to control B lymphocyte differentiation, from pre-B to mature- $\mathrm{B}$, and the function of mature B lymphocytes. miR-150 expression is enhanced in the lymph nodes and spleen during $\mathrm{T}$ and $\mathrm{B}$ cell maturation [80]. Zhou et al. illustrated that abnormal miR-150 expression in hematopoietic stem cells deeply impaired the formation of mature B cells [81]. Chen et al. found that miR-181 was expressed in mouse marrow and that abnormal miR-181 expression led to an increased fraction of B lymphocytes in adult mice [82]. Recently, miR-34a has been shown to regulate $\mathrm{B}$ cell development in murine bone marrow [83]. A study by Rao showed that miR-34a 
blocked the transition from pro-B cell to pre-B cell and reduced the maturation rate of B cells by targeting Foxp1.

miR-155 regulates the activation and function of B cells [84]. Chronic lymphocytic leukemia (CLL) cells with enhanced miR-155 expression silenced Src homology 2 domains containing inositol polyphosphate phosphatase 1 (SHIP-1) protein, which activated in response to B-cell receptor (BCR) ligation [85]. Conversely, transfection miR-155 inhibitor to CLL cells had the opposite effects. Based on ectopic miR-155 expression transgenic mouse model, Sandhu indicated that miR-155 can targets histone deacetylase 4 (HDAC4) and impairs transcriptional activity of B-cell lymphoma 6 (BCL6) [86]. miR-155 has been shown to target the transcription factors PU.1 and AID, which are regulators of Ig diversification [87]. Another study demonstrated that miR-181b directly targeted AID [88]. In other words, miR-155 and miR-181b regulate the activation of B cells by specifically targeting the transcription factor AID. In summary, the above-mentioned studies show that specific miRNAs are critical for the development a function of B cells. These miRNAs bind to key target genes that are mainly involved in transcriptional regulation and cell death pathways.

\section{Conclusions}

There is an elevated incidence of immune diseases in drug abusers. The role of miRNA in the immune system and drug abuse represents a rapidly developing area of research. The function of most miRNAs in relation to drug abuse and immune diseases is still not clearly understood. Most of the studies detected abnormal miRNA expression in chronic drug abuse and aberrant miRNA expression that affected the immune system. Unfortunately, the molecular mechanisms regarding how drug abuse changes miRNA expression levels and leads to immune system diseases is poorly understood. We aim to develop additional studies to understand the specific mechanisms. When we clearly understand the mechanisms, miRNAs can be used as potential non-invasive biomarkers with therapeutic aims to treat the immunity diseases of drug abusers.

The authors would like to apologize to those whose work they did not cite.

This work was supported by the medical and public health technology research projects of Wuxi technology bureau (CSE31N1613).

The authors declare no conflict of interest.

\section{References}

1. United Nations Office on Drugs, and Crime (UNODC) (2013): World Drug Report 2013.
2. Hyman SE, Malenka RC (2001): Addiction and the brain: the neurobiology of compulsion and its persistence. Nat Rev Neurosci 2: 695-703.

3. Wang J, Barke RA, Ma J, et al. (2008): Opiate abuse, innate immunity, and bacterial infectious diseases. Arch Immunol Ther Exp 56: 299-309.

4. Baldwin GC, Tashkin DP, Buckley DM, et al. (1997): Marijuana and cocaine impair alveolar macrophage function and cytokine production. Am J Respir Crit Care Med 156: 16061613.

5. Szabo G, Mandrekar P (2009): A recent perspective on alcohol, immunity, and host defense. Alcohol Clin Exp Res 33: 220-232.

6. McAllister-Sistilli CG, Caggiula AR, Knopf S, et al. (1998): The effects of nicotine on the immune system. Psychoneuroendocrinology 23: 175-187.

7. Pellegrino T, Bayer BM (1998): In vivo effects of cocaine on immune cell function. J Neuroimmunol 83: 139-147.

8. Sun XY, Lu J, Zhang L, et al. (2015): Aberrant microRNA expression in peripheral plasma and mononuclear cells as specific blood-based biomarkers in schizophrenia patients. J Clin Neurosci 22: 570-574.

9. Song HT, Sun XY, Zhang L, et al. (2014): A preliminary analysis of association between the down-regulation of microRNA-181b expression and symptomatology improvement in schizophrenia patients before and after antipsychotic treatment. J Psychiatr Res 54: 134-140.

10. Hsu R, Schofield CM, Dela Cruz CG, et al. (2012): Loss of microRNAs in pyramidal neurons leads to specific changes in inhibitory synaptic transmission in the prefrontal cortex. Mol Cell Neurosci 50: 283-292.

11. Dai R, Ahmed SA (2011): MicroRNA, a new paradigm for understanding immunoregulation, inflammation, and autoimmune diseases. Transl Res 157: 163-179.

12. Renthal W, Kumar A, Xiao G, et al. (2009): Genome-wide analysis of chromatin regulation by cocaine reveals a role for sirtuins. Neuron 62: 335-348.

13. Hollander JA, Im HI, Amelio AL, et al. (2010): Striatal microRNA controls cocaine intake through CREB signaling. Nature 466: 197-202.

14. Im HI, Hollander JA, Bali P, et al. (2010): MeCP2 controls $\mathrm{BDNF}$ expression and cocaine intake through homeostatic interactions with microRNA-212. Nat Neurosci 13: 1120-1127.

15. Xu LF, Wang J, Lv FB, et al. (2013): Functions of microRNA in response to cocaine stimulation. Genet Mol Res 12: 61606167.

16. Nudelman AS, DiRocco DP, Lambert TJ, et al. (2010): Neuronal activity rapidly induces transcription of the CREB-regulated microRNA-132, in vivo. Hippocampus 20: 492-498.

17. Klein ME, Lioy DT, Ma L, et al. (2007): Homeostatic regulation of MeCP2 expression by a CREB-induced microRNA. Nat Neurosci 10: 1513-1514.

18. Chandrasekar V, Dreyer JL (2009): microRNAs miR-124, let-7d and miR-181a regulate cocaine-induced plasticity. Mol Cell Neurosci 42: 350-362.

19. Chandrasekar V, Dreyer JL (2011): Regulation of MiR-124, Let-7d, and MiR-181a in the accumbens affects the expression, extinction, and reinstatement of cocaine-induced conditioned place preference. Neuropsychopharmacology 36 : 1149-1164.

20. López-Bellido R, Barreto-Valer K, Sánchez-Simón FM, et al. (2012): Cocaine modulates the expression of opioid receptors and miR-let-7d in zebrafish embryos. PLoS One 7: e50885. 
21. Saba R, Störchel PH, Aksoy-Aksel A, et al. (2012): Dopamine-regulated microRNA MiR-181a controls GluA2 surface expression in hippocampal neurons. Mol Cell Biol 32: 619632.

22. Chen CL, Liu H, Guan X (2013): Changes in microRNA expression profile in hippocampus during the acquisition and extinction of cocaine-induced conditioned place preference in rats. J Biomed Sci 20: 96.

23. Barreto-Valer K, López-Bellido R, Macho Sánchez-Simón F, et al. (2012): Modulation by cocaine of dopamine receptors through miRNA-133b in zebrafish embryos. PLoS One 7: e52701.

24. Ng TK, Carballosa CM, Pelaez D, et al. (2012): Nicotine alters microRNA expression and hinders human adult stem cell regenerative potential. Stem Cells Dev 22: 781-790.

25. Huang W, Li MD (2009): Nicotine modulates expression of miR-140*, which targets the 3'-untranslated region of dynamin 1 gene (Dnm1). Int J Neuropsychopharmacol 12: 537546.

26. Zhang Y, Pan T, Zhong X, et al. (2014): Nicotine upregulates microRNA-21 and promotes TGF- $\gamma$-dependent epithelial-mesenchymal transition of esophageal cancer cells. Tumour Biol 35: 7063-7072.

27. Maccani MA, Avissar-Whiting M, Banister CE, et al. (2010): Maternal cigarette smoking during pregnancy is associated with downregulation of miR-16, miR-21, and miR-146a in the placenta. Epigenetics 5: 583-589.

28. Shan H, Zhang Y, Lu Y, et al. (2009): Downregulation of miR-133 and miR-590 contributes to nicotine-induced atrial remodelling in canines. Cardiovasc Res 83: 465-472.

29. Wang L, Li X, Zhou Y, et al. (2014): Downregulation of miR-133 via MAPK/ERK signaling pathway involved in nicotine-induced cardiomyocyte apoptosis. Naunyn Schmiedebergs Arch Pharmacol 387: 197-206.

30. Takahashi K, Yokota S, Tatsumi N, et al. (2013): Cigarette smoking substantially alters plasma microRNA profiles in healthy subjects. Toxicol Appl Pharmacol 272: 154-160.

31. Wu Q, Zhang L, Law PY, et al. (2009): Long-term morphine treatment decreases the association of $\mu$-opioid receptor (MOR1) mRNA with polysomes through miRNA23b. Mol Pharmacol 75: 744-750.

32. He Y, Yang C, Kirkmire CM, et al. (2010): Regulation of opioid tolerance by let-7 family microRNA targeting the $\mu$ opioid receptor. J Neurosci 30: 10251-10258.

33. Zheng H, Zeng Y, Zhang X, et al. (2010): mu-Opioid receptor agonists differentially regulate the expression of miR-190 and NeuroD. Mol Pharmacol 77: 102-109.

34. Tatro ET, Hefler S, Shumaker-Armstrong S, et al. (2013): Modulation of BK channel by microRNA-9 in neurons after exposure to HIV and methamphetamine. J Neuroimmune Pharmacol 8: 1210-1223.

35. Sathyan P, Golden HB, Miranda RC (2007): Competing interactions between micro-RNAs determine neural progenitor survival and proliferation after ethanol exposure: evidence from an ex vivo model of the fetal cerebral cortical neuroepithelium. J Neurosci 27: 8546-8557.

36. Wang LL, Zhang Z, Li Q, et al. (2009): Ethanol exposure induces differential microRNA and target gene expression and teratogenic effects which can be suppressed by folic acid supplementation. Hum Reprod 24: 562-579.

37. Bahi A, Dreyer JL (2013): Striatal modulation of BDNF expression using microRNA124a-expressing lentiviral vectors impairs ethanol-induced conditioned-place preference and voluntary alcohol consumption. Eur J Neurosci 38: 2328-2337.

38. Qi Y, Zhang M, Li H, et al. (2014): MicroRNA-29b regulates ethanol-induced neuronal apoptosis in the developing cerebellum through SP1/RAX/PKR cascade. J Biol Chem 289: 10201-10210.

39. Mizuo K, Katada R, Okazaki S, et al. (2012): Epigenetic regulation of MIR-124 under ethanol dependence and withdrawal. Nihon Arukoru Yakubutsu Igakkai Zasshi 47: 155-163.

40. Pietrzykowski AZ, Friesen RM, Martin GE, et al. (2008): Posttranscriptional regulation of BK channel splice variant stability by miR-9 underlies neuroadaptation to alcohol. Neuron 59: 274-287.

41. Tapocik JD, Solomon M, Flanigan M, et al. (2013): Coordinated dysregulation of mRNAs and microRNAs in the rat medial prefrontal cortex following a history of alcohol dependence. Pharmacogenomics J 13: 286-296.

42. Dong X, Liu H, Chen F, et al. (2014): MiR-214 promotes the alcohol-induced oxidative stress via down-regulation of glutathione reductase and cytochrome $\mathrm{P} 450$ oxidoreductase in liver cells. Alcohol Clin Exp Res 38: 68-77.

43. Kenny PJ (2014): Epigenetics, microRNA, and addiction. Dialogues Clin Neurosci 16: 335.

44. Asquith M, Pasala S, Engelmann F, et al. (2014): Chronic ethanol consumption modulates growth factor release, mucosal cytokine production, and microRNA expression in nonhuman primates. Alcohol Clin Exp Res 38: 980-993.

45. Lewohl JM, Nunez YO, Dodd PR, et al. (2011): Up-regulation of microRNAs in brain of human alcoholics. Alcohol Clin Exp Res 35: 1928-1937.

46. Taganov KD, Boldin MP, Chang KJ, et al. (2006): NF-kB-dependent induction of microRNA miR-146, an inhibitor targeted to signaling proteins of innate immune responses. Proc Natl Acad Sci U S A 103: 12481-12486.

47. Hou J, Wang P, Lin L, et al. (2009): MicroRNA-146a feedback inhibits RIG-I-dependent Type I IFN production in macrophages by targeting TRAF6, IRAK1, and IRAK2. J Immunol 183: 2150-2158.

48. Chassin C, Kocur M, Pott J, et al. (2010): miR-146a mediates protective innate immune tolerance in the neonate intestine. Cell Host Microbe 8: 358-368.

49. Pauley KM, Stewart CM, Gauna AE, et al. (2011): Altered miR-146a expression in Sjogren's syndrome and its functional role in innate immunity. Eur J Immunol 41: 2029-2039.

50. Rebane A, Runnel T, Aab A, et al. (2014): MicroRNA-146a alleviates chronic skin inflammation in atopic dermatitis through suppression of innate immune responses in keratinocytes. J Allergy Clin Immunol 134: 836-847.

51. Schulte LN, Westermann AJ, Vogel J (2013): Differential activation and functional specialization of miR-146 and miR-155 in innate immune sensing. Nucleic Acids Res 41: 542-553.

52. Curtis AM, Fagundes CT, Yang G, et al. (2015): Circadian control of innate immunity in macrophages by miR-155 targeting Bmal1. Proc Natl Acad Sci U S A 112: 7231-7236.

53. Cai X, Yin Y, Li N, et al. (2012): Re-polarization of tumor-associated macrophages to pro-inflammatory M1 macrophages by microRNA-155. J Mol Cell Biol 4: 341-343.

54. Ghorpade DS, Leyland R, Kurowska-Stolarska M, et al. (2012): MicroRNA-155 is required for Mycobacterium bovis BCG-mediated apoptosis of macrophages. Mol Cell Biol 32: 2239-2253.

55. Koch M, Mollenkopf HJ, Klemm U, et al. (2012): Induction of microRNA-155 is TLR-and type IV secretion system-de- 
pendent in macrophages and inhibits DNA-damage induced apoptosis. Proc Natl Acad Sci U S A 109: E1153-E1162.

56. Cardoso AL, Guedes JR, Pereira de Almeida L, et al. (2012): miR-155 modulates microglia-mediated immune response by down-regulating SOCS-1 and promoting cytokine and nitric oxide production. Immunology 135: 73-88.

57. Wang P, Hou J, Lin L, et al. (2010): Inducible microRNA-155 feedback promotes type I IFN signaling in antiviral innate immunity by targeting suppressor of cytokine signaling 1 . J Immunol 185: 6226-6233.

58. Richmond TK, Tili E, Chiabai M, et al. (2015): Functional Interaction of Mir-155, a pro-inflammatory microRNA, and quaking in the innate immune response. J Allergy Clin Immunol 135: AB97.

59. Lu C, Huang X, Zhang X, et al. (2011): miR-221 and miR155 regulate human dendritic cell development, apoptosis, and IL-12 production through targeting of p27kip1, KPC1, and SOCS-1. Blood 117: 4293-4303.

60. Zhou H, Huang X, Cui H, et al. (2010): miR-155 and its starform partner miR-155* cooperatively regulate type I interferon production by human plasmacytoid dendritic cells. Blood 116: 5885-5894.

61. Martinez-Nunez RT, Louafi F, Friedmann PS, et al. (2009): MicroRNA-155 modulates the pathogen binding ability of dendritic cells (DCs) by down-regulation of DC-specific intercellular adhesion molecule-3 grabbing non-integrin (DCSIGN). J Biol Chem 284: 16334-16342.

62. Wanet A, Tacheny A, Arnould T, et al. (2012): miR-212/132 expression and functions: within and beyond the neuronal compartment. Nucleic Acids Res 40: 4742-4753.

63. Nahid MA, Yao B, Dominguez-Gutierrez PR, et al. (2013): Regulation of TLR2-mediated tolerance and cross-tolerance through IRAK4 modulation by miR-132 and miR-212. J Immunol 190: 1250-1263.

64. Chen RF, Huang HC, Ou CY, et al. (2010): MicroRNA-21 expression in neonatal blood associated with antenatal immunoglobulin E production and development of allergic rhinitis. Clin Exp Allergy 40: 1482-1490.

65. Sheedy FJ, Palsson-McDermott E, Hennessy EJ, et al. (2010): Negative regulation of TLR4 via targeting of the proinflammatory tumor suppressor PDCD4 by the microRNA miR-21. Nat Immunol 11: 141-147.

66. Ebert PJ, Jiang S, Xie J, et al. (2009): An endogenous positively selecting peptide enhances mature $\mathrm{T}$ cell responses and becomes an autoantigen in the absence of microRNA miR181a. Nat Immunol 10: 1162-1169.

67. Li QJ, Chau J, Ebert PJ, et al. (2007): miR-181a is an intrinsic modulator of T cell sensitivity and selection. Cell 129: 147-161.

68. Li G, Yu M, Lee WW, et al. (2012): Decline in miR-181a expression with age impairs $\mathrm{T}$ cell receptor sensitivity by increasing DUSP6 activity. Nat Med 18: 1518-1524.

69. Vigorito E, Kohlhaas S, Lu D, et al. (2013): miR-155: an ancient regulator of the immune system. Immunol Rev 253 : 146-157.

70. Kuchen S, Resch W, Yamane A, et al. (2010): Regulation of microRNA expression and abundance during lymphopoiesis. Immunity 32: 828-839.

71. Blüml S, Bonelli M, Niederreiter B, et al. (2010): Essential role of microRNA-155 in the pathogenesis of autoimmune arthritis in mice. Arthritis Rheum 63: 1281-1288.

72. O'Connell RM, Kahn D, Gibson WS, et al. (2010): MicroRNA-155 promotes autoimmune inflammation by enhancing inflammatory T cell development. Immunity 33: 607-619.
73. Rodriguez A, Vigorito E, Clare S, et al. (2007): Requirement of bic/microRNA-155 for normal immune function. Science 316: 608-611.

74. Thai TH, Calado DP, Casola S, et al. (2007): Regulation of the germinal center response by microRNA-155. Science 316 : 604-608.

75. Cardoso AL, Guedes JR, Pereira de Almeida L, et al. (2012): miR-155 modulates microglia-mediated immune response by down-regulating SOCS-1 and promoting cytokine and nitric oxide production. Immunology 135: 73-88.

76. Lu LF, Thai TH, Calado DP, et al. (2009): Foxp3-dependent microRNA155 confers competitive fitness to regulatory T cells by targeting SOCS1 protein. Immunity 30: 80-91.

77. Curtale G, Citarella F, Carissimi C, et al. (2010): An emerging player in the adaptive immune response: microRNA-146a is a modulator of IL-2 expression and activation-induced cell death in T lymphocytes. Blood 115: 265-273.

78. Lu LF, Boldin MP, Chaudhry A, et al. (2010): Function of miR-146a in controlling Treg cell-mediated regulation of Th1 responses. Cell 142: 914-929.

79. Rusca N, Monticelli S (2011): MiR-146a in immunity and disease. Mol bio inter 2011: 1-7.

80. Xiao C, Calado DP, Galler G, et al. (2007): MiR-150 controls B cell differentiation by targeting the transcription factor c-Myb. Cell 131: 146-159.

81. Zhou B, Wang S, Mayr C, et al. (2007): miR-150, a microRNA expressed in mature B and T cells, blocks early B cell development when expressed prematurely. Proc Natl Acad Sci U S A 104: 7080-7085.

82. Chen CZ, Li L, Lodish HF, et al. (2004): MicroRNAs modulate hematopoietic lineage differentiation. Science 303: 83-86.

83. Rao DS, O'Connell RM, Chaudhuri AA, et al. (2010): MicroRNA-34a perturbs B lymphocyte development by repressing the forkhead box transcription factor Foxp1. Immunity $33: 48-59$.

84. Zhang Y, Roccaro AM, Rombaoa C, et al. (2012): LNA-mediated anti-miR-155 silencing in low-grade B-cell lymphomas. Blood 120: 1678-1686.

85. Chen L, Cui B, Zhang S, et al. (2014): MicroRNA-155 In chronic lymphocytic leukemia influences B-cell receptor signaling. Cancer Res 74: S975-975.

86. Sandhu SK, Volinia S, Costinean S, et al. (2012): miR-155 targets histone deacetylase 4 (HDAC4) and impairs transcriptional activity of B-cell lymphoma 6 (BCL6) in the E $\mu$ miR-155 transgenic mouse model. Proc Natl Acad Sci U S A 109: 20047-20052.

87. Dorsett Y, McBride KM, Jankovic M, et al. (2008): MicroRNA-155 suppresses activation-induced cytidine deaminase-mediated Myc-Igh translocation. Immunity 28: 630-638.

88. de Yébenes VG, Belver L, Pisano DG, et al. (2008): miR$181 \mathrm{~b}$ negatively regulates activation-induced cytidine deaminase in B cells. J Exp Med 205: 2199-2206. 